\title{
CONTRIBUIÇÃO PRELIMINAR AOS TIPOS POLINICOS DA TRIBO MUTISIEAE (COMPOSITAE) 1
}

\author{
Grace Irene Imbiriba Pastana 2
}

\begin{abstract}
RESUMO - O presente trabalho é um estudo palinilógico de quartoze espécies brasileiras da Tribo Mutisieae, pertencentes ao Herbário do Museu Nacional - RJ (R). São dadas as respectivas descrições polínicas com desenhos dos grãos em vistas equatorial e polar, da L.O. e detalhe da exina. Acompanham uma tabela referente ao tratamento estatístico e dois diagramas comparativos. Palavras-chave: Pólen, Mutisieae, Palinologia.
\end{abstract}

\begin{abstract}
The present paper is a palynological study of the fourteen species of the Tribe Mutisieae, belong to the Museum Nacional Herbary - RJ (R). Several aspects relating caracteristics of Mutisieae pollen are treated such as polar and equatorial diameter, L. O.: table of statistical treatment and comparative diagrams are displayed.

Key words: Pollen, Mutisieae, Palynology.
\end{abstract}

\section{Introdução}

A família Compositae constitui-se no maior grupo natural das Dicotiledoneae, em termos de números de representantes (Baker 1873).

A distribuição taxonômica em tribo é bem marcante, o que também ocorre com o táxon gênero (Baker 1873; Bentham 1876; Hoffmann 1889). Há, porém, em cada tribo, importantes problemas de sistemática no que concerne às espécies, particularmente com as Mutisieae.

O objetivo deste trabalho é contribuir para o levantamento dos atributos polínicos do material brasileiro da tribo em foco, permitindo com segurança uma boa triagem do táxon.

\section{Material e Métodos}

O material palinológico foi retirado de quatorze exsicatas do Herbário do Museu Nacional do Rio de Janeiro (R).

Para o processo de lise, usou-se o método clássico de acetólise (Erdtman 1960). Das lâminas resultantes, procedeu-se à mensuração de trinta grãos escolhidos aleatoriamente.

$\mathrm{Na}$ determinação da forma dos grãos, considerou-se a relação entre as médias dos diâmetros polar (P) e equatorial $(\mathrm{E})$.

Para a determinação do comprimento e da largura do colpo e da endoabertura, do lado do apocolpo, da espessura da exina e da relação sexina/nexina, foi estabelecida a média de cerca de dez grãos medidos.

A classificação dos grãos de pólen quanto ao tamanho e quanto ao índice de espessamento da exina foi baseada em Moreira et al. (1981).

${ }^{1}$ Parte da pesquisa realizada nos anos de 1984 e 85, com Bolsa de Aperfeiçoamento - CNPq. Os dados fornecem subsídios à dissertação de Mestrado da autora, em fase de elaboração.

2 Estagiária do Departamento de Botânica do Museu Nacional, cursando o Mestrado da Instituição com auxílio de Bolsa da CAPES. 
No tratamento estatístico usou-se o desvio padrão da média, o erro padrão, o intervalo de confiança de $95 \%$ e o coeficiente de variabilidade.

Com o auxílio do microscópio "Zeiss Jena" - Amplival, usando objetiva de 40X e 100X (imersão), foram feitas as mensurações e observações e os desenhos, realizados com o uso de microscópio com câmara clara "Zeiss", objetiva de 40X e completados à mão livre com nanquim.

A terminologia utilizada baseia-se em Barth \& Melhem (1988).

Todas as medidas são expressas em micrômetros $(\mu \mathrm{m})$.

\section{Resultados}

Jungia floribunda Less. Lâm. 1343 - Grãos sub-prolatos (35,0-42,5 x 30,0-40,0), tamanho médio, 3-colporados com superfície reticulada. Colpo ca. 29,5 X 2,50; endoabertura lalongada, ca. 1,53 x 6,25. Âmbito triangular, fossaperturado. Apocolpo ca. 18,0. Exina espessa, ca. 7,0; sexina ca. 4,75; teto com báculos finos, simples e curtos; báculos infratectais, espessos e ramificados; nexina dividida em duas camadas.

Material estudado: Local: Cruz Alta - RS; col.: Lindman 736, em 30.III.1893; det.: Rev. G. Nilsson 1979.

J. selowii Less. Lâm. 1344 - Grãos sub-prolatos (32,5 - 40,0 x 27,5 - 32,5), tamanho médio, 3-colporados, com superfície reticulada. Colpo ca. 28,5 x 2,5; endoabertura lalongada, ca. 3,05 x 10,75. Âmbito triangular, fossaperturado. Apocolpo ca. 14,0. Exina espessa, ca. 5,0; sexina ca. 2,5; teto com báculos finos, simples e curtos; báculos infratectais espessos e ramificados; nexina dividida em duas camadas.

Material estudado: Local: Bom Retiro - SC; col.: P. R. Reitz 3628, em 24. XII.1948; det.: Rev. G. Nilsson 1979.

Trixis antimenohrroea (Schrank.) Mart. Lâm. 1345 - Grãos prolatos (45,0 - 52,5 x 30,0 - 33,75), tamanho médio, 3-colporados, com elevações polares e superfície reticulada. Colpo ca. $35,75 \times 2,5$; endoabertura lalongada, ca. 1,62 x 6,12. Âmbito triangular, fossaperturado. Apocolpo ca. 17,08. Exina espessa, ca. 5,36; sexina ca. 2,92; teto com báculos finos, simples e curtos; báculos infratectais espessos e ramificados; nexina dividida em duas camadas.

Material estudado: Local: Barra da Tijuca - RJ; col.: B. Flaster 40, em 26.VI.1959; det.: G. M. Barroso.

T. lessingii DC. Lâm. 1346 - Grãos prolatos $(35,0$ - 38,75 x 23,75 - 28,75), tamanho médio, 3-colporados, com elevações polares e superfície reticulada. Colpo ca. 27,0 x 1,7; endoabertura lalongada, ca. 1,35 x 7,41. Âmbito triangular, fossaperturado. Apocolpo ca. 17,5. Exina espessa, ca. 5,0; sexina ca. 2,7; teto com báculos finos, simples e curtos; báculos infratectais espessos e ramificados; nexina dividida em duas camadas.

Material estudado: Local: Curitiba - PR; col.: P. Dusén 2371 em 24.II.1903;det.: G. M. Barroso.

Chaptalia integerrima (Vell.) Burk. Lâm. 1349 - Grãos prolato-esferoidais (32,5 - 47,5 x 30,0 - 40,0), tamanho médio, 3-colporados com superfície suavemente espiculada. Colpo ca. 32,75 x 2,75; endoabertura lalongada, ca. 4,0 x 12,75. Âmbito triangular, fossaperturado. Apocolpo ca. 20,5. Exina espessa, ca. 5,75; sexina ca. 3,75; teto com báculos finos, simples e curtos; báculos infratectais espessos e ramificados; nexina dividida em duas camadas.

Material estudado: Local: Vineta - SP; col.: A. Loefgren 17, em 7.VIII.1887; det.: G. M. Barroso.

C. nutans (L.) Polak. Lâm. 1350 - Grãos prolato-esferoidais (37,5 - 42,5 x 32,5 37,5), tamanho médio, 3-colporados com superfície espiculada. Colpo ca. 30,62 x 3,33; endoabertura lalongada, ca. $3,98 \times 10,83$. Âmbito triangular fossaperturado. Apocolpo 
ca. 27,0. Exina espessa, ca. 4,84; sexina ca. 3,28; teto com báculos finos, simples e curtos; báculos infratectais espessos e ramificados; nexina dividida em duas camadas.

Material estudado: Local: Tijuca - RJ; col.: M. H. Vale, em 7.II.1944; det.: G. M. Barroso.

Mutisia campanulata Less. Lâm. 1347 - Grãos prolatos (72,5 - 100,0 x 60,0 - 70,0), tamanho grande, 3-colporados com superfície espiculada. Colpo ca. 62,5 x 7,25; endoabertura lalongada, ca. $8,79 \times 27,25$. Âmbito triangular, fossaperturado. Apocolpo ca. 32,0. Exina espessa, ca. 11,0; sexina ca. 6,88; teto com báculos finos, simples e curtos; báculos infratectais espessos e ramificados; nexina dividida em duas camadas.

Material estudado: Local: Ibituruna - SC; col.: L. Emydio 10, em 9.II.1948; det.: G. M. Barroso.

M. coccinea St. Hill. Lâm. 1348 - Grãos prolatos (75,0 - 87,5 x 50,0 - 67,5), tamanho grande, 3-colporados com superfície espiculada. Colpo ca. 66,5 x 6,75; endoabertura lalongada, ca. $9,18 \times 28,5$. Âmbito triangular, fossaperturado. Apocolpo ca. 24,27. Exina espessa, ca. 7,7; sexina ca. 6,25; teto com báculos finos, simples e curtos; báculos infratectais espessos e ramificados; nexina dividida em duas camadas.

Material estudado: Local: SC; col.: Santos et al.; em 13.x.1971; det.: G. M. Barroso.

Gochnatia discoidea (Less.) Cabr. Lâm. 1353 - Grãos sub-prolatos (47,5 - 58,75 x 40,0 - 50,0), tamanho grande, 3-colporados, com superfície acentuadamente espiculada. Colpo ca. $34,5 \times 2,43$; endoabertura lalongada, ca. 4,71 x 15,25. Âmbito triangular, fossaperturado. Apocolpo ca. 24,27. Exina espessa, ca. 7,7; sexina ca. 6,25; teto com báculos finos, simples e curtos; báculos infratectais espessos e ramificados; nexina dividida em duas camadas.

Material estudado: Local: Caeté - MG; col.: Mello Barreto 4229, em 29.II.1933; det.: Mello Barreto.

G. amplexifolia (Gardn.) Cabr. Lâm. 1354 - Grãos subprolatos (47,5 - 53,75 x 41,25 - 47,5), tamanho grande, 3-colporados com superfície acentuadamente espiculada. Colpo ca. 36,12 x 6,25; endoabertura lalongada, ca. 4,89 X 19,12. Âmbito triangular, fossaperturado. Apocolpo ca. 22,21. Exina espessa, ca. 7,88; sexina ca. 4,64; teto com báculos finos simples e curtos; báculos infratectais espessos e ramificados; nexina dividida em duas camadas.

Material estudado: Local: Brejo das Almas - MG; col.: Mello Barreto 12.300, em 10.XI.1938; det.: Paul C. Standley-Field Museum.

G. cordata Less. Lâm. 1355 - Grãos sub-prolatos $(38,75$ - 47,5 x 32,5 - 38,75), tamanho médio, 3-colporados, com superfície acentuadamente espiculada. Colpo ca. 30,12 x 3,50; endoabertura lalongada, ca. 3,15 x 16,87. Âmbito triangular, fossaperturado. Apocolpo ca. 22,7. Exina espessa, ca. 6,25; sexina ca. 3,55; teto com báculos finos, simples e curtos; báculos infratectais espessos e ramificados; nexina dividida em duas camadas.

Material estudado: Local: S. Leopoldo - RS; col.: J. Eugênio 42, em 1940; det.: G. M. Barroso.

G. paniculata (Less.) Cabr. Lâm. 1356 - Grãos-prolato-esferoidais $(35,0$ - 47,5 x $32,5-40,0)$, tamanho médio, 3-colporados com superfície acentuadamente espiculada. Colpo ca. 30,28 x 2,5; endoabertura lalongada, ca. 3,93 x 14,28. Âmbito triangular, fossaperturado. Apocolpo ca. 20,0. Exina espessa, ca. 5,0; sexina ca. 2,75: teto com báculos finos, simples e curtos; báculos infratectais espessos e ramificados; nexina dividida em duas camadas.

Material estudado: Local: Campos da Bocaina - SP; Col.: Glaziou 10098, em 8.IX.1879; det.: A. L. Cabrera.

Holocheilus pinnatifidus (Less.) Cabr. Lâm. 1351 - Grãos prolato-esferoidais (33,75 - 42,5 x 30,0 - 41,25), tamanho médio, 3-colporados, com elevações polares pequenas e superfície reticulada. Colpo ca. 29,25 x 2,5; endoabertura lalongada, ca. 1,14 x 8,25. Âmbito triangular, fossaperturado. Apocolpo ca. 16,5. Exina espessa, ca. 6,25; sexina 
ca. 5,0; teto com báculos finos, simples, curtos, báculos infratectais espessos e ramificados; nexina dividida em duas camadas.

Material estudado: Local: Serra dos Órgãos - RJ; col. eq. do Gab. Bot. Esc. Politéc., em 27.III.1883; det.: G.M. Barroso.

Stifftia crysantha Mikan. Lâm. 1352 - Grãos prolatos (75,0 - 87,5 x 50,0 - 52,5), tamanho grande, 3-colporados com superfície espiculada. Colpo ca. 60,3 x 2,5; endoabertura lalongada, ca. 7,36 x 23,25. Âmbito triangular, fossaperturado. Apocolpo ca. 25,83. Exina espessa, ca. 9,17; sexina ca. 6,67; teto com báculos finos, simples e curtos; báculos infratectais espessos e ramificados; nexina dividida em duas camadas.

Material estudado: Local; Rio D’Ouro - RJ; col.: Franklin et Glaziou, em 23.VIII.1879, det.: G. M. Barroso.

\section{Discussão e Conclusão}

As espécies examinadas de sete gêneros da Tribo Mutiseae apresentaram variação na forma, no tamanho e na ornamentação da superfície. Diferenças encontradas nas medidas dos grãos, após o tratamento estatístico (ver tabela) e segundo constam nas descrições respectivas, não são significativas e apontam para uma certa homogeneidade dentro de cada gênero.

Wodehouse (1929 a,b), no primeiro trabalho, afirma que os dois caracteres marcantes dos grãos das espécies da subtribo Nassauvinae, por ele investigadas e da qual fazem parte os gêneros Jungia, Trixis e Holocheilus, são a ausência de espinhos e o acentuado alongamento dos colpos. Por outro lado, destaca a presença de elevações polares èm Trixis que observamos também em Holocheilus pinnatifidus, apesar de pequenas. $\mathrm{O}$ autor evidencia, além disso, a fina e distinta textura granular, pouco variada, em relação à grande maioria das Mutisieae restantes, que têm como característica uma textura grosseira dos grãos. No outro trabalho, considera os espículos pronunciados e esferoidais dos grãos das espécies de Gochnatia, diferentemente daqueles encontrados nas espéciés de Mutisia, que são de tamanho grande e forma elipsoidal, com espículos mais adelgaçados. Chaptalia também exibiu grãos esferoidais, no entanto com uma superfície finamente granular. Nossos resultados, mesmo não coincidindo completamente em relação à superfície dos grãos do último gênero, concordam com as demais observações do autor, inclusive porque, em geral, as espécies são diversas das nossas, particularmente as de Chaptalia cuja variação em função do tamanho dos espículos não chega a contrariar seu tipo de grão de pólen.

Em sua caracterização dos tipos polínicos para a tribo Mutisiaea, Stix (1960) apresenta as definições dos tipos Trixis e Mutisia nas quais se enquadram basicamente as nossas descrições, para as espécies dos respectivos gêneros. Nesse sentido, os grãos de Stifftia crysantha, cujas características morfológicas são muito semelhantes aos de Mutisia, talvez possam ser incluídos no tipo polínico deste último gênero.

Analisando os grãos das espécies de Mutisia como subsídios à sua revisão genérica, Cabrera (1965) assinala como predominantes as formas prolata e subprolata. Especialmente $M$. coccinea apresentou, segundo o autor, forma subprolata que diferiu de nós que a assinalamos como prolata. Ele declara que a "forma e o tamanho dos grãos variam entre as espécies do gênero, inclusive em variedades de uma mesma espécie, fazendo-o acreditar que possam existir séries de poliplóides no grupo".

Salgado-Laboriau (1973) analisou grãos de Trixis verbasciformis e seus dados confirmaram o tipo Trixis de Stix, como presentemente, os nossos.

Em trabalho mais recente, Moreira et al. (1981) investigaram grãos de três espécies de Gochnatia incluídas neste nosso estudo: G. discoidea, G. paniculata e G. amplexifolia. Seus resultados são confirmados pelos nossos, a exceção de pequena diferença nas medidas da última espécie que modificou a determinação da forma, prolata para eles 
e sub-prolata para nós.

Do exposto, podemos concluir que, a princípio, cada gênero representa um tipo polínico em si, à exceção de Stifftia crysantha que poderá ser situado naquele de Mustisia. As diferenças ocorridas nos grãos das espécies de Gochnatia e nas de Chaptalia denotam que talvez uma subtipificação seja necessária visando a um bom arranjo palinológico para a tribo citada.

\section{Agradecimentos}

Ao Prof. Titular Álvaro Xavier Moreira, nosso orientador do Curso de Mestrado, recentemente falecido, que foi de grande importância na elaboração do presente trabalho com o concurso das suas idéias e generoso apoio.

Aos colegas, Profs. Vânia e Roberto L. Esteves, pelas opiniões e incentivos.

\section{Referências Bibliográficas}

BAKER, J. A. 1873. Compositae. In: MARTIUS, C.F.P. Flora Brasiliensis... v. 6, pt. 3, P. $1-442$.

BARTH, O.M. \& MELHEM, T.S. 1988. Glossário Ilustrado de Palinologia, Campinas, UNICAMP. 75 p.

BENTHAM, G. 1876. Compositae. In: BENTHAM, G. \& HOOKER, J.D. Genera Plantarum... London, I.L. Revue, v. 2, pt. 1 p. 484-504.

CABRERA, A.L. 1965. Revision del Género Mutisia (Compositae). Op. Lilloana, Tucuman, 13: 1-327, il.

ERDTMAN, G. 1960. The acetolysis method. A revised description, Svensk Bot. Tidskr. Stockolm. 54:561-64.

HOFFMANN, O. 1889. Compositae. In: ENGLER, A. \& PRANT, K. Die Natturlichen Pflanzenfamiliem... Leipzig, Wilhelm Engelman. v. 4, pt. 5, p. 87-387.

MOREIRA, A.X.; LEITE, N.A.S.; ESTEVES, R.L.\& ESTEVES, V.G.L. 1981. Estudo Palinológico das Espécies Brasileiras da Tribu Mutisieae (Compositae) I. Bol. Mus. Nac. Rio de Janeiro, n. s. Bot., Rio de Janeiro, 64: 1-13, 11.

SALGADO-LABORIAU, M.L. 1973. Contribuição à palinologia dos Cerrados. Rio de Janeiro, Acad. Bras. Ciênc, 291 p., il.

STIX, E. 1960. Pollen Morphologishe Wittersunchengen und Compositen. Grana Palynol., Stockolm, 2 (2): 41-104, il.

WODEHOUSE, R.P. 1929a. Pollen Grains in the identification and classification of plants - III. The Nassauvinae. Bull. Torrey bot. Cl., Lancaster, 56: 123-38., il.

WODEHOUSE, R.P. 1929b. Pollen Grains in the identification and classification of plants. IV The Mutisieae. Amer. J. Bot., Lancaster, 16: 297-313., il. 


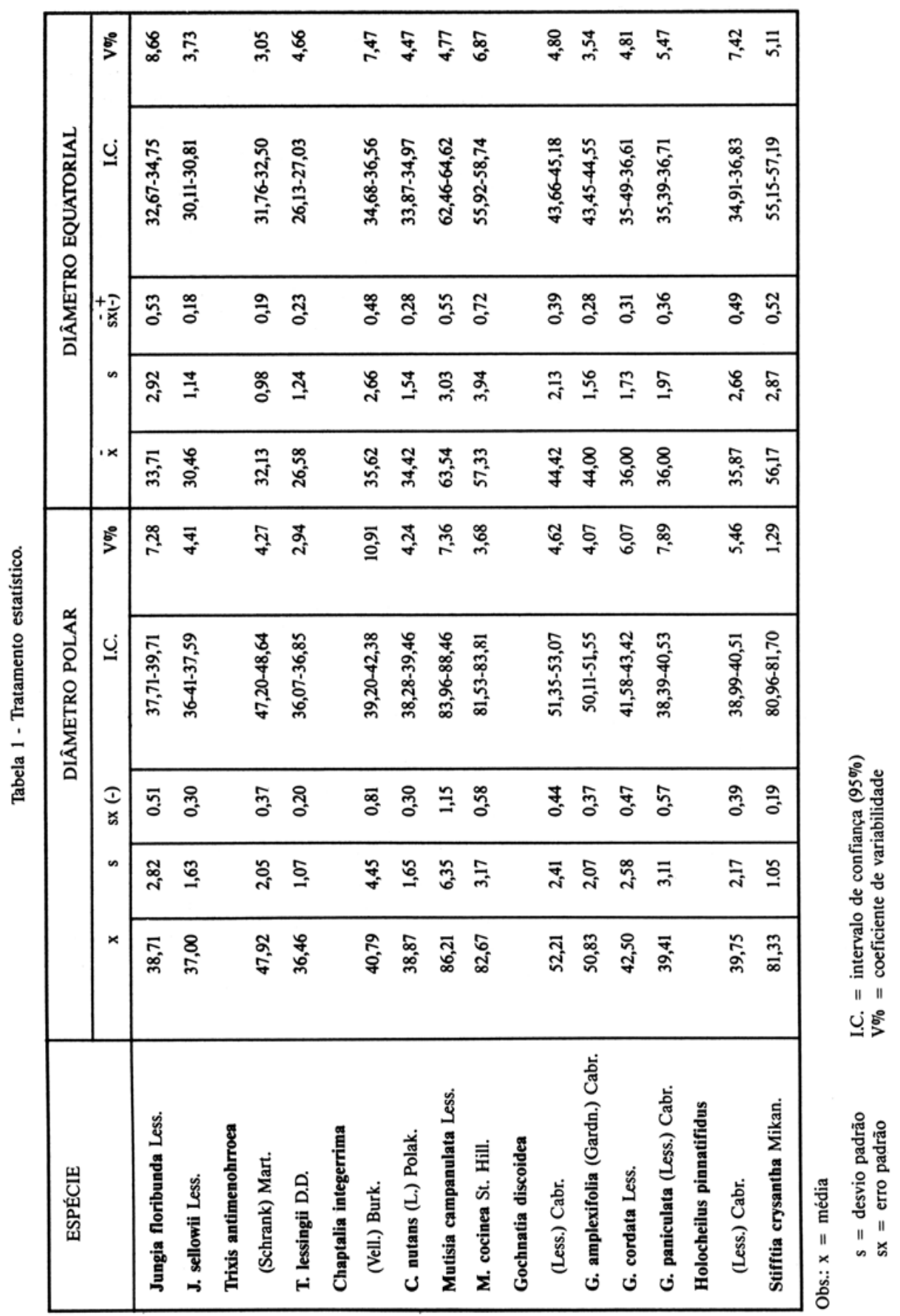




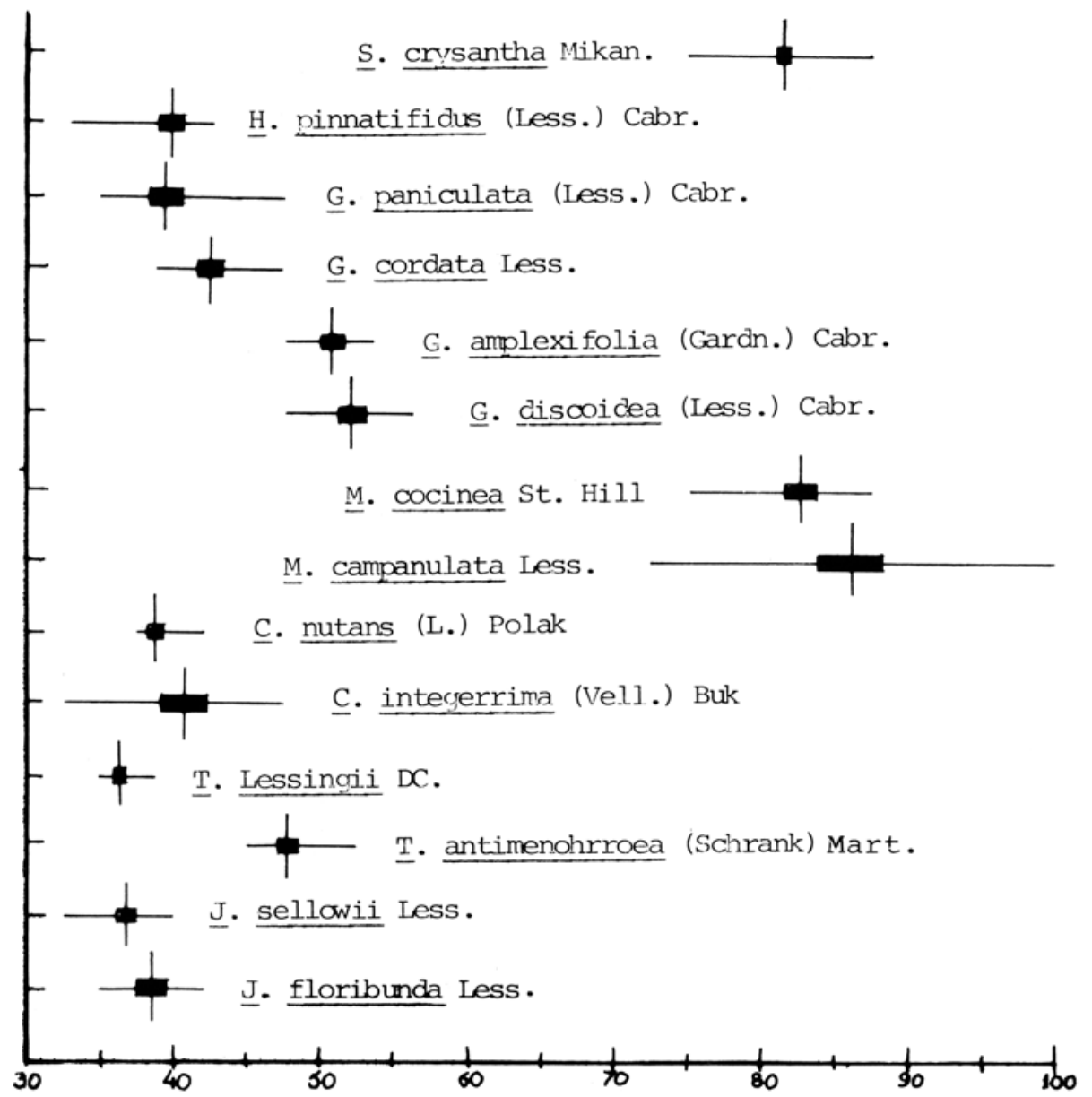

Significado dos símbolos nos Gráficos 1 e 2: linha horizontal = "range" *;retângulo = intervalo de confiança de $95 \%$; linha vertical = média aritmética.

Gráfico 1 - Diagrama comparativo do Diâmetro Polar dos grãos de pólen das espécies em estudo. *"range" = medidas extremas de cada diâmetro (ver descriçð̌es). 


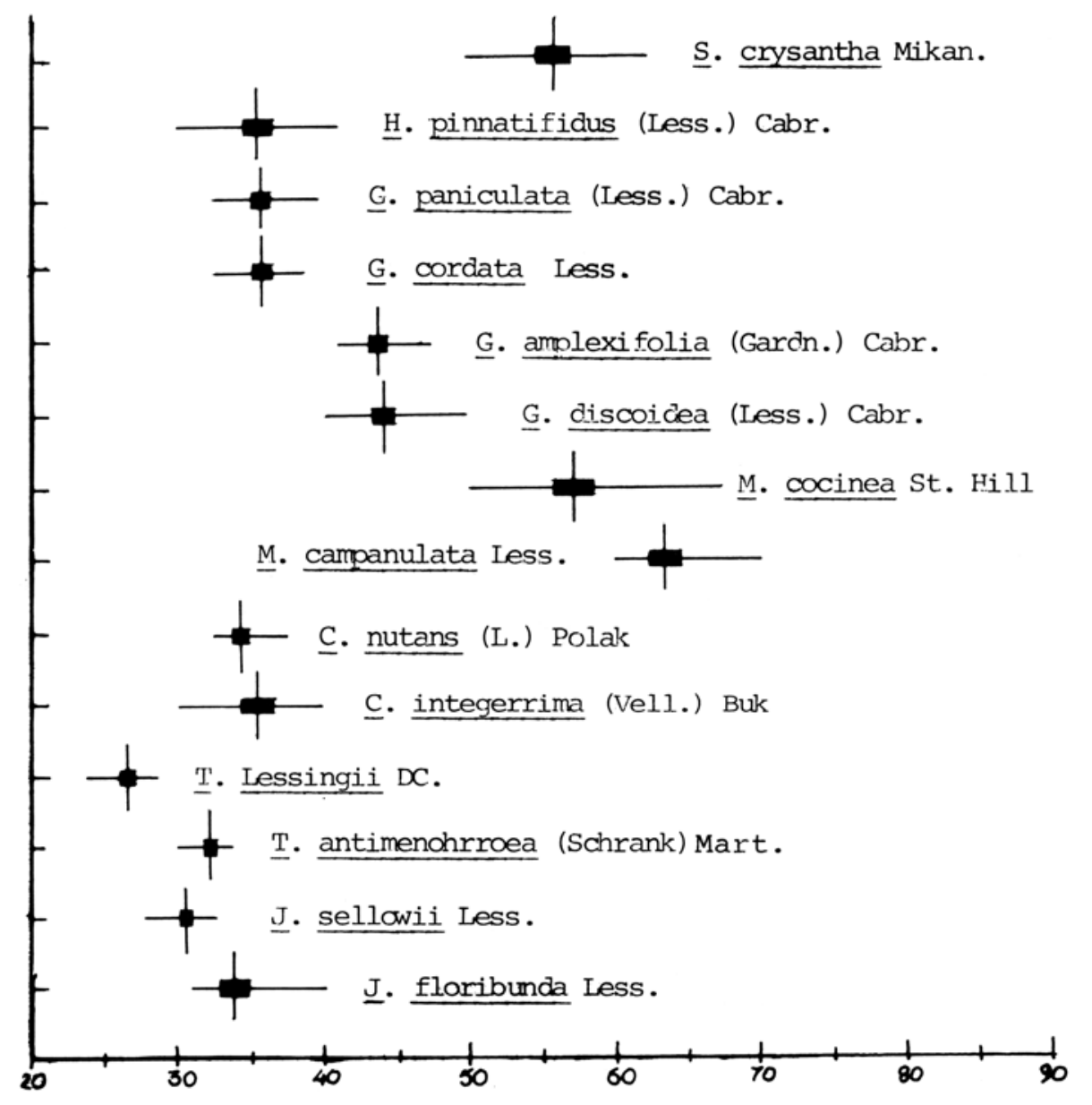

Gráfico 2 - Diagrama comparativo do Diâmetro Equatorial dos grãos de pólen das espécies em estuđo. 
c
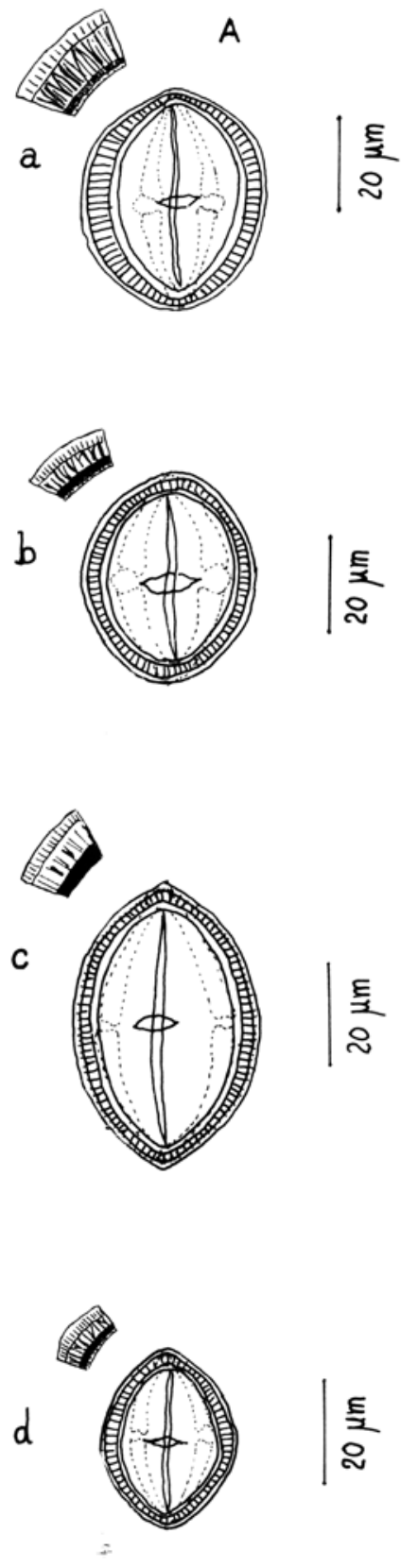
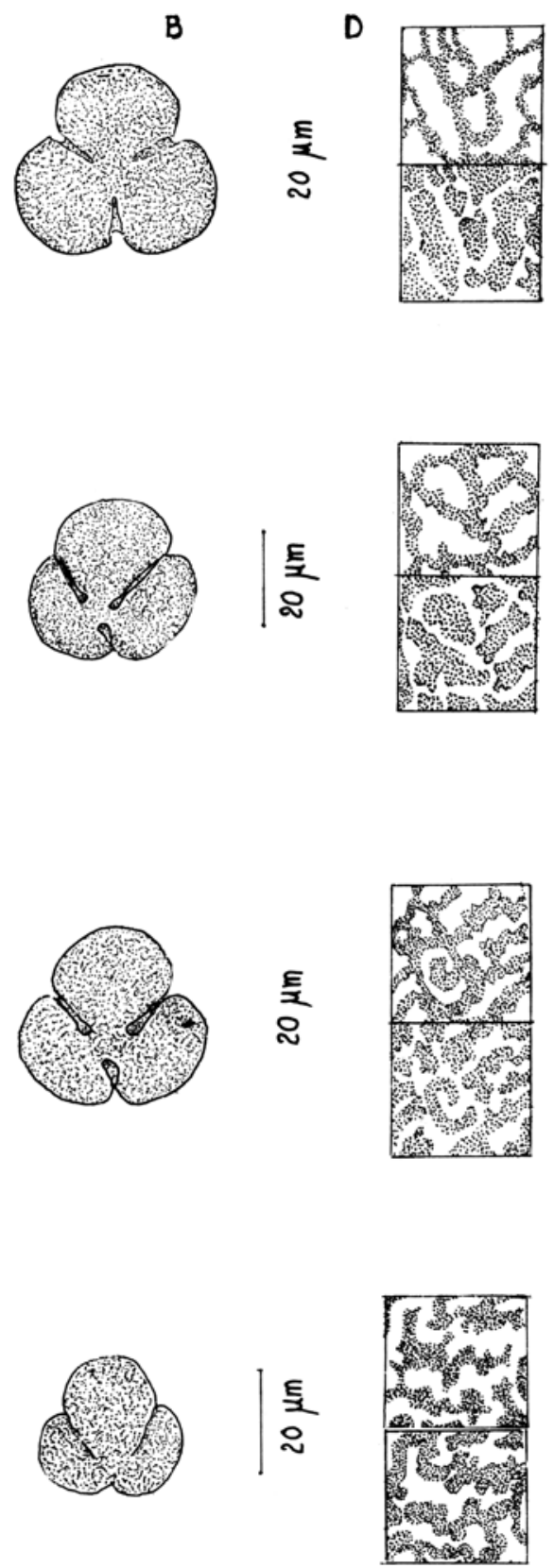

Figuras 1-4: A - Vista equatorial em corte-ótico; B - Vista polar com aspecto da superfície; C - Detalhe da exina; D - Análise do L.O. 1: a. Jungia floribunda Less.; b) Jungia selowii Less.; c) Trixis antimenoh rroea (Schrank.) Mart.; d.T. lessingii DC. 


\section{C}
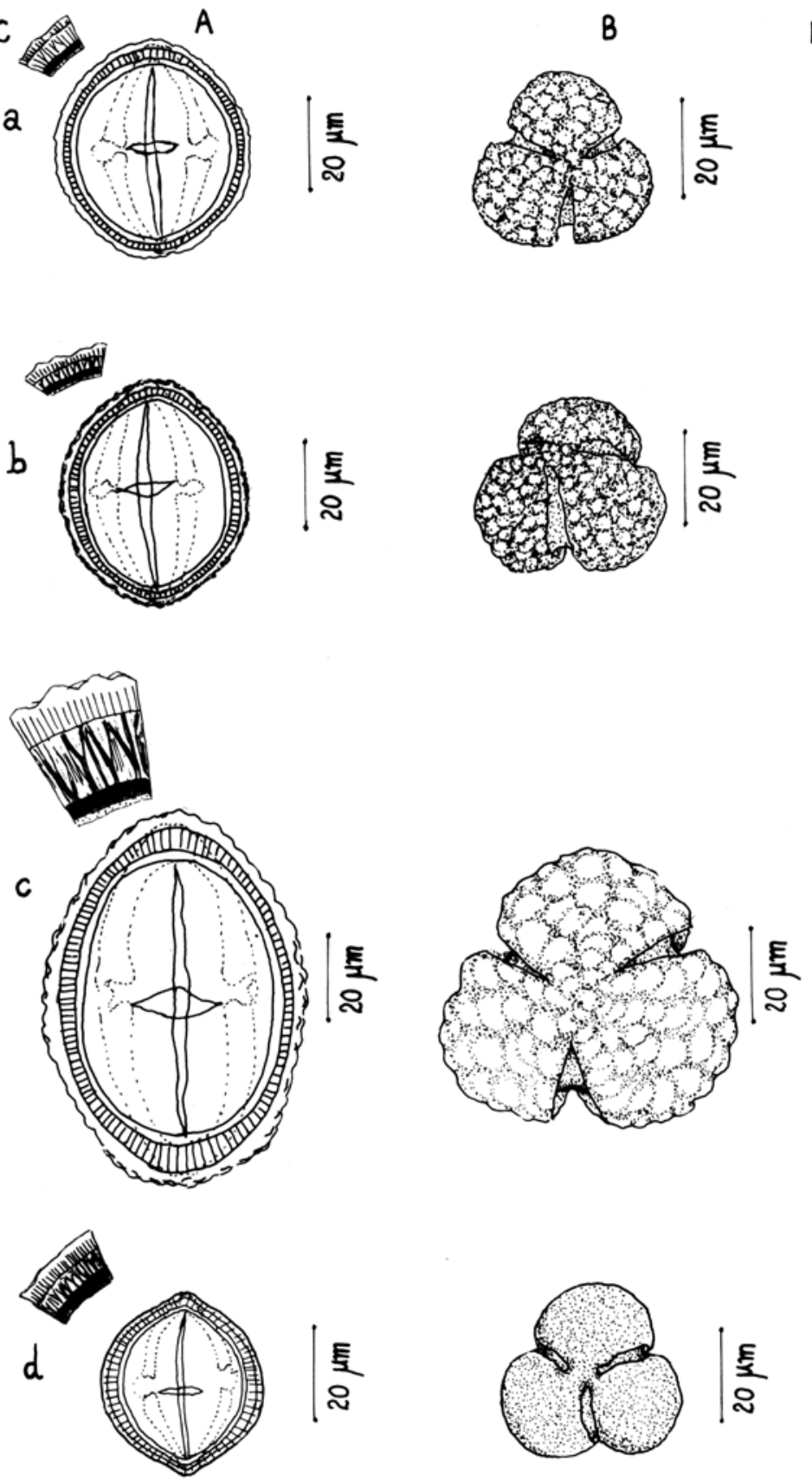
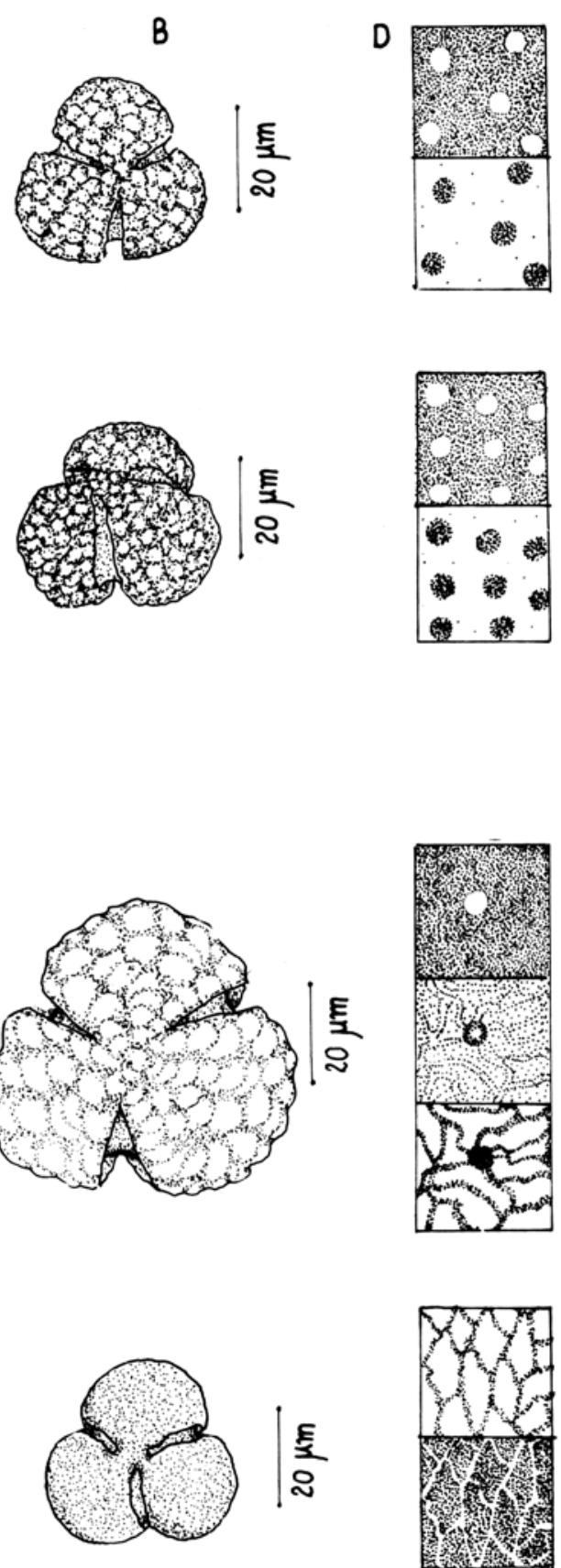

Figura 2: a Chaptalia integerrima (Vell.) Buk.; b. Chaptalla nutans (L.) Polak.; c. Stifftia crysantha Mikan: d. Holocheilus pinnatifidus (Less.) Cabr. 

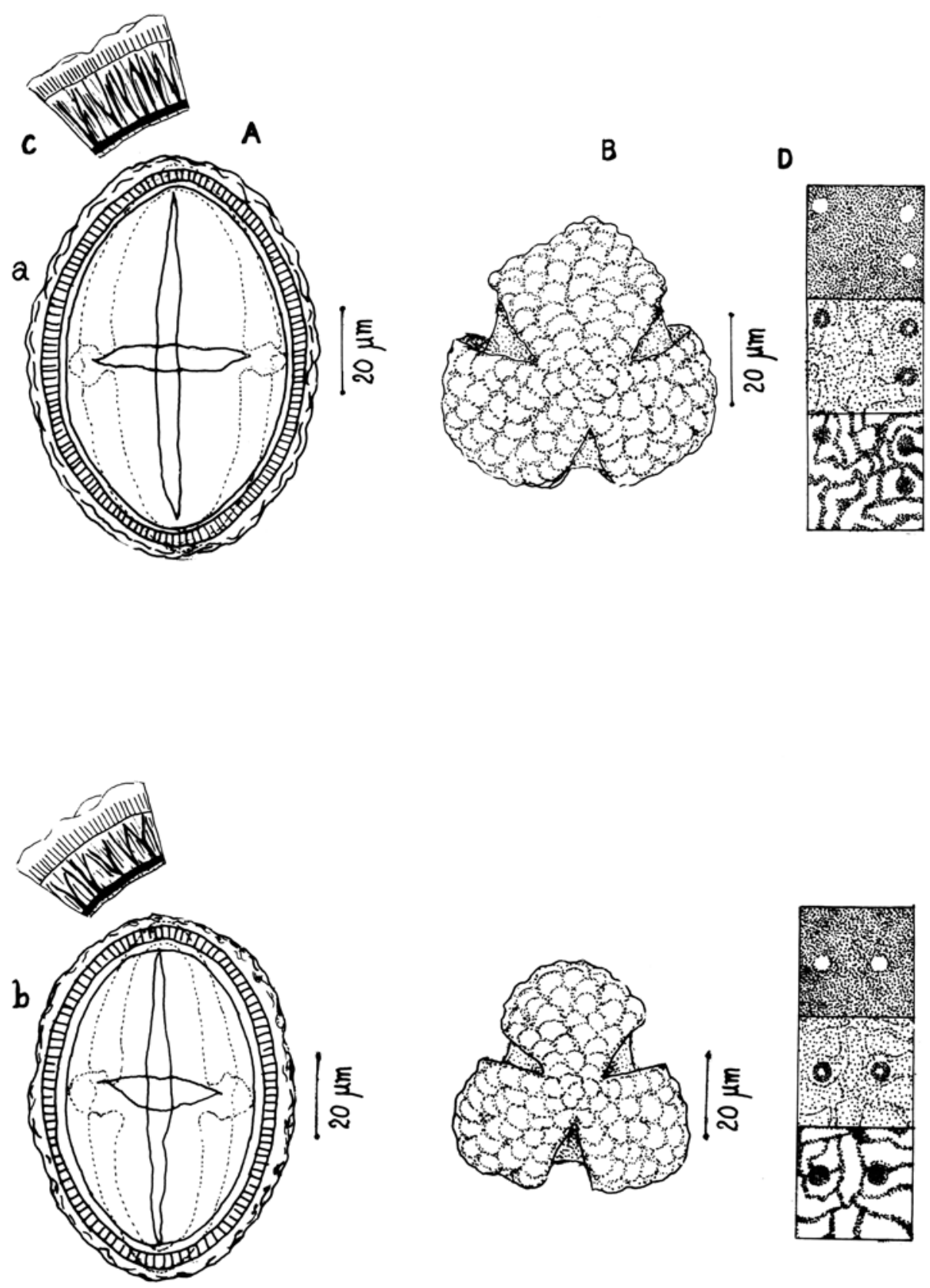

Figura 3: a. Mutisia campanulata Less.; b. Mutisia cocinea St. Hill. 

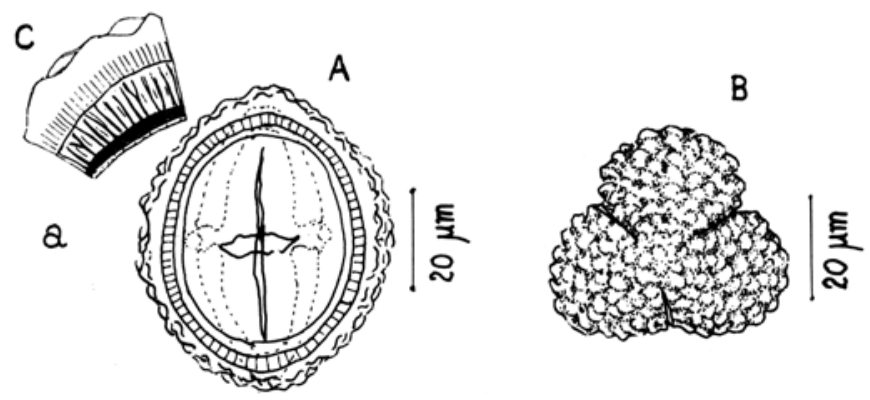

D
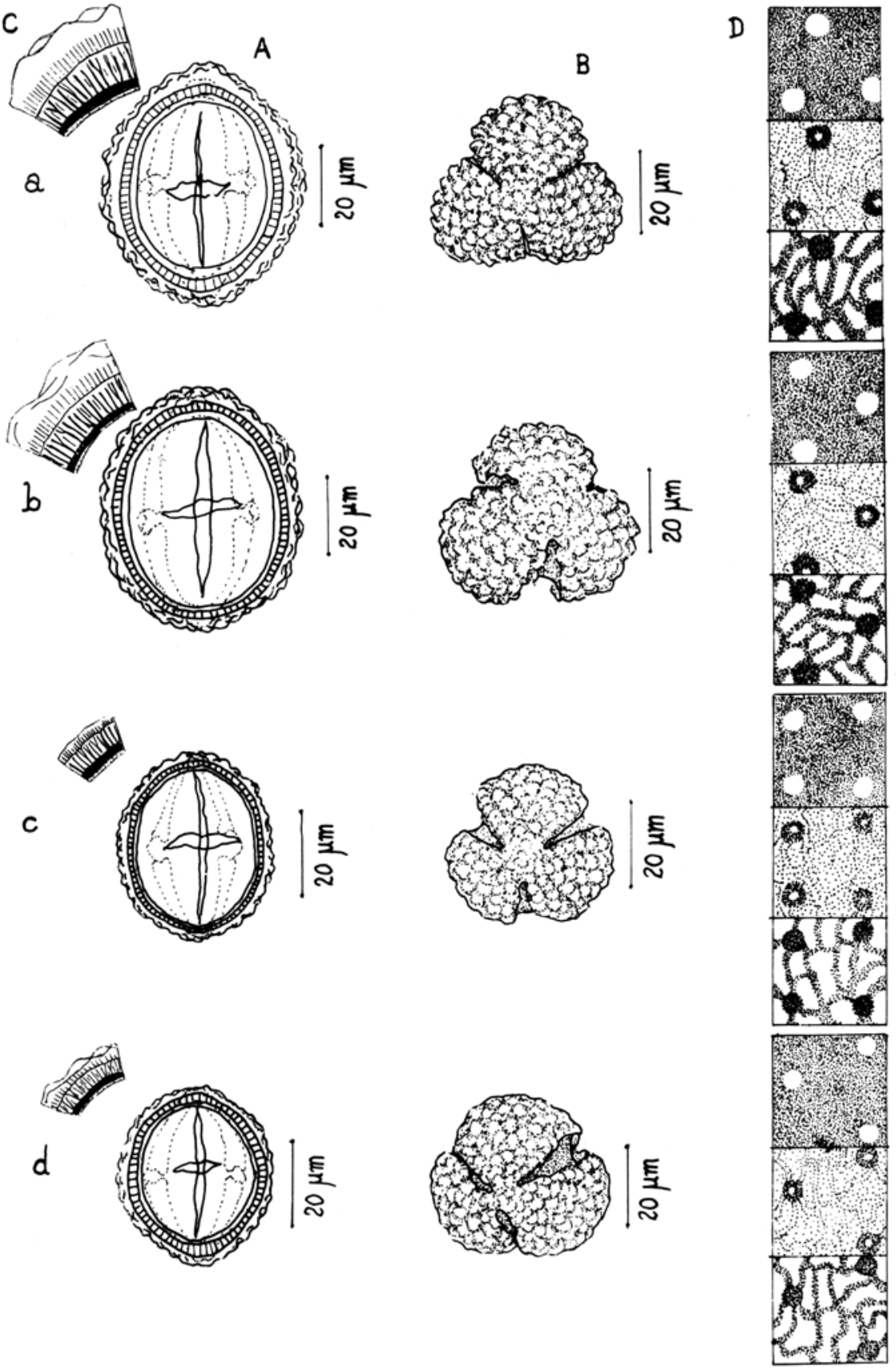

Figura 4: a. Gochnatia discoidea (Less.) Cabr.; b. G. amplexifolia (Gardn.) Cabr.; c. G. cordata Less.; d. G. paniculata (Less.) Cabr. 